\title{
Daily oxygen consumption rhythms of Senegalese sole solea senegalensis (Kaup, 1858) juveniles
}

\author{
Maria F. Castanheira *, Catarina I.M. Martins, Sofia Engrola, Luís E.C. Conceição \\ Centro de Ciências do Mar (CCMar), Universidade do Algarve, Campus de Gambelas, 8005-139 Faro, Portugal
}

\section{A R T I C L E I N F O}

\section{Article history:}

Received 13 October 2010

Received in revised form 12 April 2011

Accepted 21 June 2011

Available online 4 August 2011

\section{Keywords:}

Activity rhythms

Flatfish

Individual variation

Light-dark cycles

Respirometry

Routine metabolism

\begin{abstract}
A B S T R A C T
Senegalese sole is known to be a species with pronounced nocturnal feeding behaviour. However, as for most fish species, there is a lack of knowledge concerning the influence of such biological rhythm on metabolic rate. The aim of this study was to determine whether individual variation in routine and fed metabolic rate was affected by daily light-dark rhythms in juveniles of Senegalese sole. The individual oxygen consumption measurements in Senegalese sole juveniles were determined by flow-through respirometry, at fasted conditions and after the fish were fed a single meal, the meal time started at $0930 \mathrm{~h}$ and fish fed ad libitum for $30 \mathrm{~min}$. The measurements were made during $22 \mathrm{~h}$, of which $8 \mathrm{~h}$ was in the light and $14 \mathrm{~h}$ in the dark, and started immediately after transfer to the respiratory chambers at $1100 \mathrm{~h}$. The results suggest an influence of light-dark cycles in routine metabolism. It was observed that oxygen consumption increased during the dark phase in fasted fish (FAST) but was higher during the light phase in fed fish (FEED). However, when feed is provided during the light phase, juveniles are capable of shifting oxygen consumption rhythms to respond to the energetic demands of digestion and growth. These results suggest that routine metabolism varies according to the species natural habits as Senegalese sole is known to be nocturnal. The findings of this study underline the importance of understanding the biological rhythms of the species under study before metabolic data are interpreted.
\end{abstract}

(c) 2011 Elsevier B.V. All rights reserved.

\section{Introduction}

The rate of respiration, measured in terms of oxygen consumption, has been frequently used as an index for metabolic rate in aquatic animals. The oxygen consumption of fish may be classified in different levels based upon the physiological state of the fish (Brett, 1971; Fry, 1971). The basal metabolism is defined by the lowest rate of energy spent to maintain a live organism (Brett, 1971; Brett and Groves, 1979). Due to fish spontaneous activity, it is difficult to measure the basal metabolism; therefore the term resting metabolism is preferably referred instead of the minimum rate of oxygen consumption (Brett, 1971; Brett and Groves, 1979). Metabolic scope is the range through which the aerobic metabolic rate of an animal is able to fluctuate (Fry, 1971). The metabolic scope due to feeding is the difference between maximum oxygen consumption measured due to feeding and the measurements at fasted level (Cunha et al., 2007; Lucas and Priede, 1992; Wieser, 1985).

Routine metabolic rate (RMR) refers to the basal metabolism plus the minimal metabolic level related to spontaneous activity (Fry, 1957; Seppänen et al., 2010). RMR has been used to understand the metabolic consequences of some stressors (Careau et al., 2008; Martins et al., 2011). In fish, metabolic rate may be influenced by a

\footnotetext{
* Corresponding author.

E-mail address: mcastanheira@ualg.pt (M.F. Castanheira).
}

large number of internal and external factors (Brett and Groves, 1979). Some researchers have reported a shift in the metabolic rate, correlated to daily photoperiod which may also be influenced by changes in the light-dark cycle (Biswas et al., 2002; Davis, 1962; Ross and McKinney, 1988). In fish, the light-dark cycle is one of the most important synchronizing factors (Aranda et al., 1999). Knowledge about behaviour has been related with daily rhythms. For example Sea bass Dicentrarchus labrax (Linnaeus, 1758) may exhibit both diurnal and nocturnal behaviour, inverting their phasing depending on the season (Sánchez-Vázquez et al., 1998). Furthermore, Oliveira et al.(2009) observed in Senegalese sole a synchronization of reproduction with daily rhythms. Daily rhythms have been profusely investigated in fish during the last two decades, with special emphasis on behavioural rhythms, reproduction and feeding activity. Biological rhythms related to behaviour and physiological parameters are controlled by endogenous variations within the brain, which are synchronized by environmental changes (Souêtre et al., 1989).

Fish exhibit daily behavioural rhythms and alternate activity patterns between light and darkness periods. In the absence of external cues (constant light), the circadian rhythms persist only with slight deviation from the environmental cycle that is normally synchronized (Sánchez et al., 2009). Nevertheless, the adaptation of the endogenous rhythm to an external cycle may become a limiting factor for physiological processes, including those related to animal growth rate (Biswas et al., 2002). 
The Senegalese sole, is a common fish in the Western Mediterranean and in the Southeast coast of the Atlantic. This species is considered a nocturnal species, since in laboratorial conditions they showed a higher activity and plasma melatonin during the night (Bayarri et al., 2004). Although it is well known that oxygen consumption follows a light-dark rhythm (De la Gándara et al., 2002), the influence of feeding on this rhythm is not yet available in Senegalese sole, or in any flatfish. Such information may be useful to understand the oxygen requirements for this species, and for advising better feeding strategies. Furthermore, the extent of individual variation in metabolism under light and dark regimes has never been reported. A full understanding of the light-dark rhythm provides basic knowledge on variability of oxygen responses and these effects may be considered when interpreting respirometry studies on stress or nutritional effects.

The aim of this study was to determine how individual variation in fasted (or routine) metabolic rate and fed metabolic rate is affected by daily light-dark cycles in Senegalese sole juveniles. In particular, it was intended to verify how Senegalese sole, a nocturnal species, is able to adjust oxygen consumption to respond to diurnal feeding.

\section{Methods}

\subsection{Fish, feeding and housing conditions}

The experiment was carried out at the Ramalhete Research Station (Faro, Portugal), using fish stocked in a partial-recirculated system (temperature: $20 \pm 1^{\circ} \mathrm{C}$; salinity: $36 \mathrm{~g} \mathrm{~L}^{-1}$; dissolved oxygen: $8.5 \pm$ $4 \mathrm{mg} \mathrm{L}^{-1}$ ) with a photoperiod of $10 \mathrm{~h}$ light: $14 \mathrm{~h}$ dark. The lights are turned on at $0800 \mathrm{~h}$ and off at $1800 \mathrm{~h}$, and it was a sudden transition from light to dark period and vice versa. This experimental period lasted for 163 days.

Twelve Senegalese sole juveniles, averaging an initial weight of $18.49 \pm 2.94 \mathrm{~g}$ were used. Fish were obtained from natural spawning of wild broodstock and reared according to standard larval and juvenile rearing protocols (Dinis et al., 1999). Fish were kept in two $12.6 \mathrm{~L}$ flatbottomed fibreglass tank $(70 \mathrm{~cm}$ length $\times 30 \mathrm{~cm}$ width $\times 6 \mathrm{~cm}$ depth). The water renewal rate in the recirculated system was $19.5 \%$ per day. Tanks were cleaned and the water parameters (temperature, salinity and dissolved oxygen) were monitored every day. The water quality was determined by weekly measurements of ammonia and nitrite using test kits and never exceeded 0.025 and $0.3 \mathrm{mg} \mathrm{L}^{-1}$, respectively, during the experimental period.

Fish were fed ad libitum, once a day a commercial diet, (Aquagold $2 \mathrm{~mm}$, Sorgal SA, Ovar, Portugal; $44 \%$ crude protein, $14 \%$ crude fat, $8 \%$ ash, $2.5 \%$ crude fibres, $1.0 \%$ phosphorus), except on days 85,106 and 113 when the oxygen consumption of FAST was measured. At the beginning of the experiment, fish were anaesthetized with, 2-phenoxyethanol (Sigma-Aldrich, Germany; 1:150 v/v), and individually weighed and marked with an intradermal injection of water ink (Acualux Titan, Spain) on the blind side, according to standard tagging protocol (Reig et al., 2003).

\subsection{Experimental procedures}

\subsubsection{Respirometry}

In the first part of experiment (acclimatization period), fish were undisturbed until day 85 , the beginning of measurements of oxygen consumption. Oxygen consumption of individual Sole juveniles was determined by flow-through respirometry on day's 85, 106 and 113 (FAST conditions) and on day's 120,127 and 134 (FEED conditions). Before transfer to the respiratory chambers fish were left unfed for $24 \mathrm{~h}$ (FAST groups $\mathrm{n}=12$ ) or fed ad libitum, the meal time started at $0930 \mathrm{~h}$ and fish fed ad libitum for 30 min. (FEED groups $n=12$ ). Measurements started immediately after transfer $(1100 \mathrm{~h})$ and continued for $22 \mathrm{~h}$, of which $8 \mathrm{~h}$ were in the light and $14 \mathrm{~h}$ in the dark. In order to keep the stress level of the fish at a minimum, the fish were not disturbed during the respirometry measurements. The body weight of each individual was determined immediately after removal from the chamber.

The flow-through respirometry system consisted in 6 individual metabolic chambers $(2.3 \mathrm{~L})$. Each fish was placed individually in a chamber. Since housing in respirometry chambers is likely to induce a stress response (Careau et al., 2008; Martins et al., 2011) the first $3 \mathrm{~h}$ of measurements taken during the period of light were discarded. The water inlet was always at oxygen saturation level while the oxygen concentration at the outlet was measured by a polarigraphic microelectrode model 8-730 (Microelectrodes Inc., USA). The measurements were controlled by a PC using the Oxilogger 2009 software (João Reis, University of Algarve, Faro, Portugal).

The saturation level of oxygen was maintained in the water reservoir, and a peristaltic pump (ISMATEC, model ISM920A, Switzerland), controlled the water flow of each chamber via Tygon ${ }^{\circledR}$ tubing (480- $\mu \mathrm{m}$ inner diameter). Each respirometry run consisted in sequential measurements from all the chambers. The magnetic valves controlled by the Oxilogger 2009 software determined in which chamber the oxygen consumption was being measured. At the beginning of each cycle the oxygen dissolved in water was measured during a $30 \mathrm{~s}$ period in order to calibrate the software. This calibration was followed by a $120 \mathrm{~s}$ washing step of seawater from the next chamber before starting the measurement period (30 s). This step was always done before and after the measurement of each chamber. Six measurements of oxygen consumption were registered over a period of $30 \mathrm{~s}$ ( $5 \mathrm{~s}$ each).A complete cycle of measurements ( 6 chambers) was done during $18 \mathrm{~min}$, and comprised the calibration of the oxygen probe, a washing step, measurement of dissolved oxygen in the water chamber, washing step, and so forth the 6 chambers in sequence. The water temperature was always measured in the outlet water of each chamber by a temperature probe. The oxygen calibration was performed each time a measurement run started.

\subsection{Statistics}

Statistical analyses were performed using SPSS 18.0 for Windows. Data are expressed as mean $\pm \mathrm{SE}$ of three runs of respirometry data. Statistical analysis was done based on the average of the three runs per fish. Therefore, for statistical analysis, the light period between 1530 and $1800 \mathrm{~h}$ was considered to be representative of resting metabolism. All measurements taken during the dark phase were used. Paired $t$-test was used to compare the oxygen consumptions between the light and dark phases. Possible correlation between oxygen consumption in light and dark phases in (FAST/FEED) fish over the experimental period were analysed using Pearson correlation tests. Linear regression was used for curve adjustment. The slopes of the regression equations were compared by analyses of covariance using Proc GML (SAS, 1989). Significance levels were set at $\mathrm{P}<0.05$.

Scope for growth, was calculated using the formula: oxygen consumption (FEED) - oxygen consumption (FAST), where, FEED and FAST were the maximum and minimum oxygen consumption rates, respectively.

\section{Results}

A pronounced individual variation in oxygen consumption was observed after fish transfer to respirometry chambers (Fig. 1). Fish under fasted conditions presented a maximum oxygen consumption of $210.3 \mu \mathrm{mol} \mathrm{O}_{2} / \mathrm{g} \mathrm{BW} / \mathrm{h}$, and a minimum oxygen consumption of $163.7 \mu \mathrm{mol} \mathrm{O}_{2} / \mathrm{g} \mathrm{BW} / \mathrm{h}$. Food ingestion led to a clear increase in oxygen consumption, to a maximum of $311.4 \mu \mathrm{mol} \mathrm{O}_{2} / \mathrm{g} \mathrm{BW} / \mathrm{h}$, while minimum oxygen consumption was $233.3 \mu \mathrm{mol} \mathrm{O}_{2} / \mathrm{g} \mathrm{BW} / \mathrm{h}$. The period of lowest oxygen consumption by fish (resting metabolism) averaged $175.1 \pm$ $2.6 \mu \mathrm{mol} \mathrm{O} / \mathrm{g} \mathrm{BW} / \mathrm{h}$.

The metabolic scope (difference between FEED and FAST metabolic rate) averaged $96.5 \pm 13.6 \mu \mathrm{mol} \mathrm{O}_{2} / \mathrm{g} \mathrm{BW} / \mathrm{h}$ and $69.9 \pm 9.1 \mu \mathrm{molO}_{2} / \mathrm{g}$ 


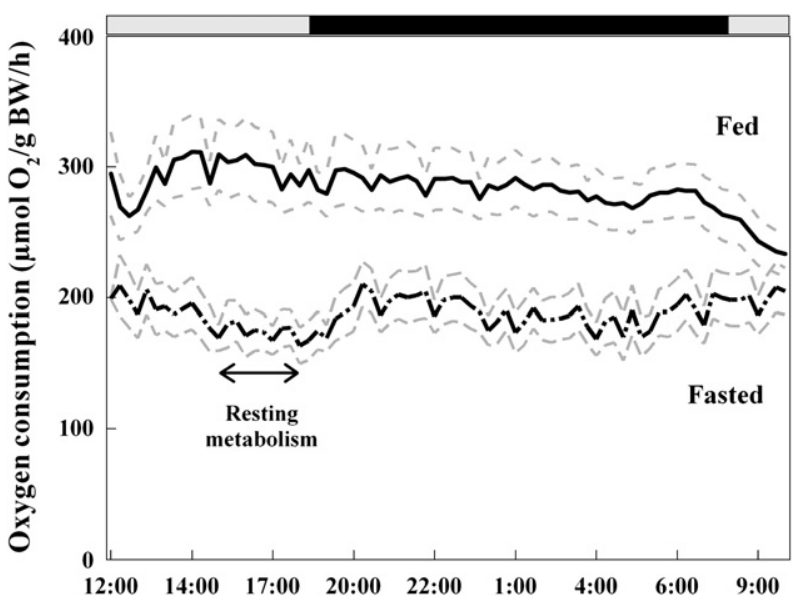

Fig. 1. Variation in oxygen consumption in 12 Senegalese sole juveniles, over a period of $22 \mathrm{~h}$. The line (--) represents oxygen consumption of Fasted and (-) Fed individuals. Black lines are means and grey lines standard errors $(n=12)$. The period of lowest oxygen consumption by fish (resting metabolism) was determined between 1530 and $1800 \mathrm{~h}$.

$\mathrm{BW} / \mathrm{h}$, in the light and dark phases, respectively. There was no significant correlation between metabolic scope and resting metabolism in Senegalese sole juveniles $(P=0.999)$.

Fish showed higher oxygen consumption $(294 \pm 3.6 \mu \mathrm{mol} \mathrm{O} / \mathrm{g}$ $\mathrm{BW} / \mathrm{h}$ ) under fed conditions than fish under fasted conditions $(200 \pm$ $6.3 \mu \mathrm{mol} \mathrm{O} / \mathrm{g} \mathrm{BW} / \mathrm{h})(\mathrm{P}<0.001)$. Fasted metabolism looks to be about 0.7 times the fed metabolism.

In the dark phase in fasted and fed conditions was found a significant difference between the oxygen consumption in fasted fish $(215 \pm 12.6 \mu \mathrm{mol} \mathrm{O} / \mathrm{g} \mathrm{BW} / \mathrm{h})$ as compared with the fed fish $(285 \pm$ $15.6 \mu \mathrm{mol} \mathrm{O2/g} \mathrm{BW/h})(\mathrm{P}<0.001)$ (Fig. 2).

In fasted conditions (FAST) juveniles showed a significantly higher oxygen consumption in the dark phase $\left(215 \pm 12.6 \mu \mathrm{mol} \mathrm{O}_{2} / \mathrm{g} \mathrm{BW} / \mathrm{h}\right)$ as compared with the light phase $(184 \pm 12.0 \mu \mathrm{mol} \mathrm{O} / \mathrm{g} \mathrm{BW} / \mathrm{h})(\mathrm{P}<0.05)$. The oxygen consumption in FEED was significantly higher in the light phase as compared with the dark phase $(\mathrm{P}<0.05)$ (Fig. 3).

One should also note the wide individual variation in oxygen consumption (Figs. 4 and 5) between individuals in similar physiological conditions (dark, light conditions either FEED or FAST). Highly significant correlations were found between fish oxygen consumption ( $\mu \mathrm{mol} \mathrm{O}_{2} / \mathrm{g} \mathrm{BW} / \mathrm{h}$ ) during the light and dark phases and FAST or FEED conditions (Fig. 4).

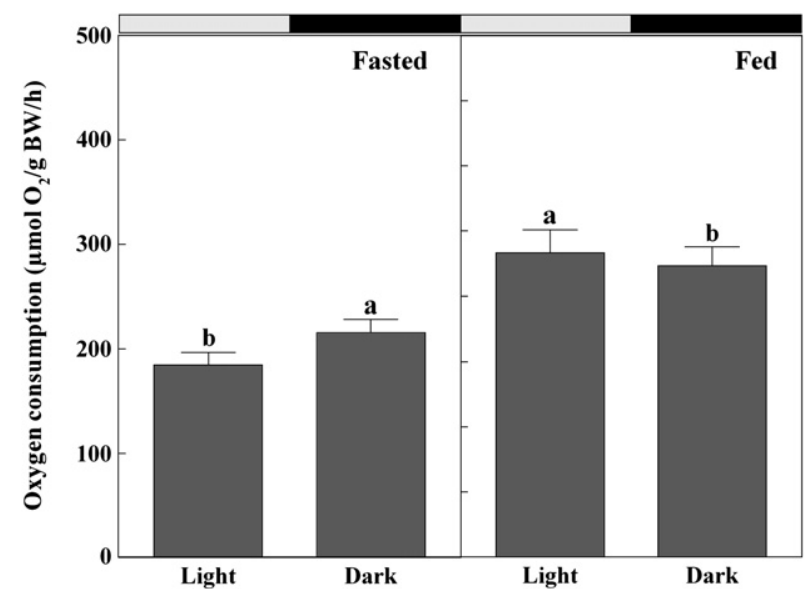

Fig. 2. Mean oxygen consumption rate of Fasted and Fed Senegalese sole juveniles $(\mathrm{n}=12)$, during the light $(8 \mathrm{~h})$ and dark $(14 \mathrm{~h})$ phases. Data are presented as means \pm se. Different letters represent significant differences (paired $t$-test Fasted conditions: $\mathrm{P}=0.003$ ) and (paired $t$-test Fed conditions: $\mathrm{P}=0.046$ ).

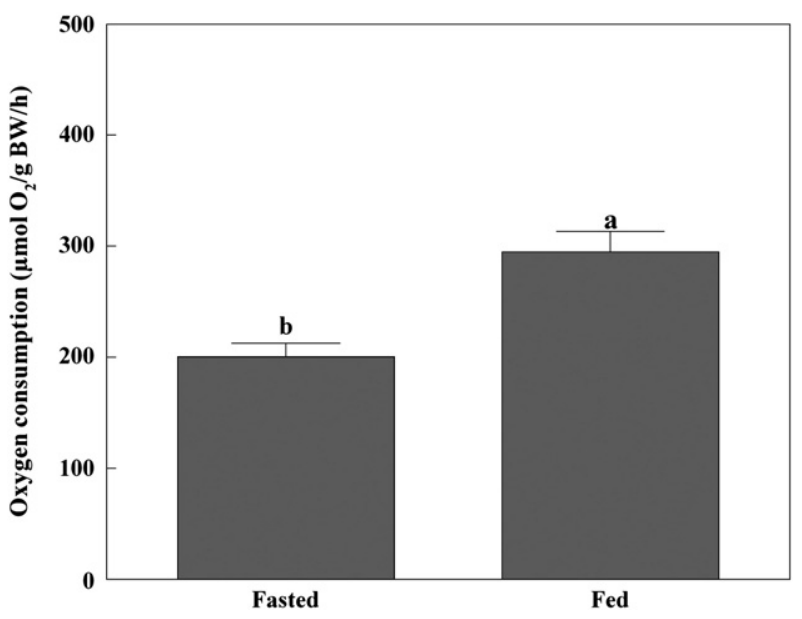

Fig. 3. Mean oxygen consumption in Fasted and Fed Senegalese sole juveniles during the $22 \mathrm{~h}$ period (light and dark phases) $(n=12)$. Data are presented as means \pm se. Different letters indicate significant differences (paired $t$-test: $\mathrm{P}<0.001$ ).

FAST condition:

MR Dark phase $=9.095+1.035 *$ MR Light phase $\left(r^{2}=0.95\right.$, $\mathrm{n}=12, \mathrm{P}<0.001$ )

FEED condition:

MR Dark phase $=70.065+0.728 *$ MR Light phase $\left(r^{2}=0.92\right.$, $\mathrm{n}=12, \mathrm{P}<0.001)$.

Individuals with higher oxygen consumption in the light phase were also the individuals with higher oxygen consumption in the dark phase.

The intercepts and slopes of the regression lines in Fig. 4 differed significantly ( $\mathrm{P}=0.030$ for intercepts and $\mathrm{P}=0.013$ for slopes). The slope of the regression line in fasted fish was significantly higher than in fed fish, suggesting that fasted fish have a more pronounced increase in oxygen consumption during the dark phase as compared with fed fish.

The FEED metabolic rate was significantly correlated, $(P=0.003)$, with the FAST metabolic rate (Fig. 5).

FEED $M R=28.057+1.343 *$ FAST $M R\left(r^{2}=0.60, n=12, \quad P=\right.$ $0.003)$.

Senegalese sole that exhibited higher oxygen consumption levels in FEED condition also exhibited higher oxygen consumption levels in FAST conditions.

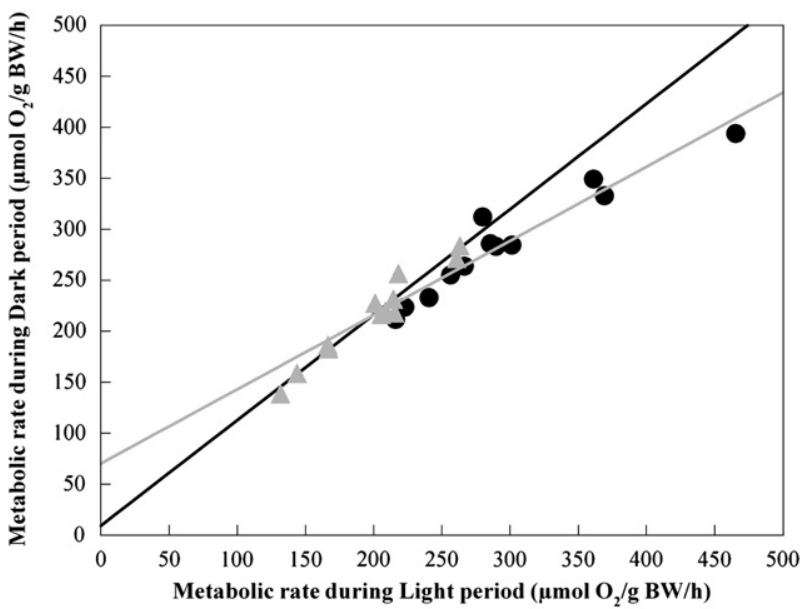

Fig. 4. Relationship between oxygen consumption levels during dark and light phase in Fasted (grey line) and Fed (dark line) Senegalese sole juveniles $(\mathrm{n}=12)$. 


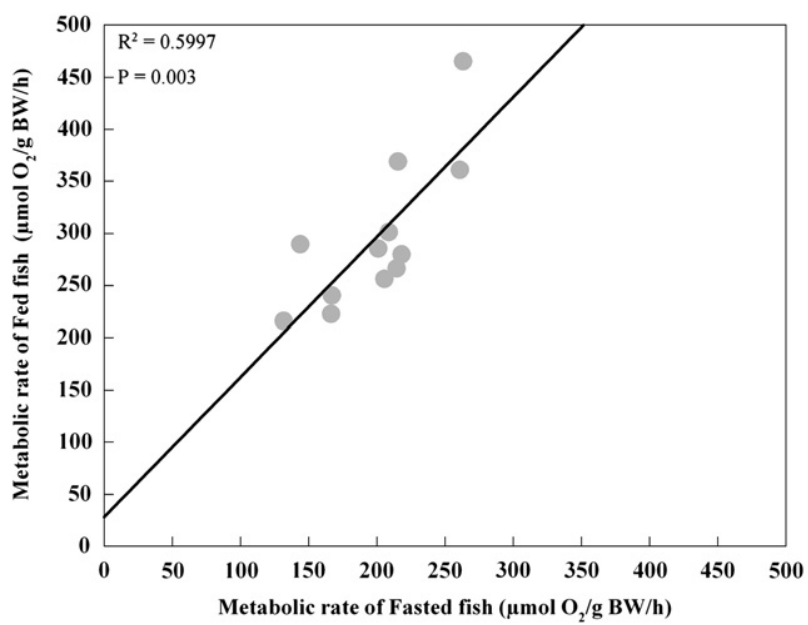

Fig. 5. Relationship between oxygen consumption in Fasted and Fed Senegalese sole juveniles $(n=12)$ during light phase.

\section{Discussion}

A better knowledge of individual differences in oxygen consumption measurements may contribute to optimise metabolic studies; however, such knowledge is often missing. The scarceness of information at level of individual variation is strongly associated to difficulty in measuring it. It requires complex techniques (e.g., individual tagging) and this implies more work and time. In this study, individual differences in oxygen consumption seem to be consistent across both FAST and FEED and during the light and dark phases. Although the absolute values of oxygen consumption were affected by the light and dark phases, the rank of each individual remained the same, i.e. an individual consuming less oxygen when fasted was also consuming less oxygen when fed. Likewise, fish consuming less oxygen during the light phase also consumes less oxygen during the dark phase. This comparison is possible because the fish was previously tagged as described in Methods. This suggests that variations in oxygen consumption measurements are persistent within individuals.

Fasted fish (FAST) showed higher oxygen consumption during the dark phase, this may suggest a higher activity during the night. Senegalese sole appears to be strongly influenced by photoperiod; however daily metabolic rate rhythm, to our knowledge has not been reported. The data of the present study is in accordance with the idea that Senegalese sole is a nocturnal species, as clearly shown by spawning and melatonin rhythms (Bayarri et al., 2004; Oliveira et al., 2009; Vera et al., 2007).

The results of FAST oxygen consumption during the dark phase suggest an anticipatory activity influenced by the natural rhythms of food availability, similar suggestion has been raised in other species, as Salmonids and European sea bass Dicentrarchus labrax Linnaeus, 1758 (Aranda et al., 1999; Reebs, 2002). In addition, once this species has a higher routine (FAST) metabolism during night. The time of the day (dark/light) during which the respirometry measurements are done should be taken into consideration when interpreting such data.

In FAST group, the oxygen consumption was higher during the dark phase. However when feeding occurred, the oxygen consumption was higher during the light phase, probably as a response to the energy costs of digestion and protein accretion (see Fig. 4). In general, feeding increases the oxygen consumption in organisms; which is associated with numerous mechanical and biochemical processes related with food ingestion, digestion absorption and assimilation as well as, protein synthesis and deposition (Fu et al., 2006; Jobling, 1981). Jobling (1994) suggested that the maximum rate of oxygen consumption induced by feeding appears to be approximately double of fasted metabolism. In FEED fish the metabolism looks to be about 0.7 times increased in relation to FAST fish. Thus, the present study may suggest a lower metabolic scope in Senegalese sole compared to Salmonids and other fish species. Alternatively, sole appetite may have been low, leading to fed intake below the maximum for this species, and, therefore the maximum metabolic rate was not attained. It should be noted that in this study feeding occurred during the light phase. Therefore the present study suggests that the individual variation in oxygen consumption is more adaptative than temporal variability. In mammals, circadian rhythms are generated by biological clocks that are synchronized to the cyclic environment by photic or nonphotic cues (Moore and Danchenko, 2002). Stimuli such as feeding may cause phase shifts in most of the circadian rhythms as it acts as strong entrainment (Mrosovsky, 1996). Meal timing is known to synchronize most of the circadian rhythms in mammals (Froy and Miskin, 2007). The timing of food availability and intake exerts a great effect on rhythmic physiology (Froy et al., 2006). It is also known that periodic food access can override the light-dark cycle (Rubin et al., 1988). In the present study, during fed conditions, the food was available regularly at the same time which may have exerted a powerful stimulus. The feed stimulus possibly override the light-dark cycle, as oxygen consumption was higher during the light phase. The higher metabolism in this phase may be due to food processing or also due to a higher metabolism derived to an adaptation to a new circadian rhythm, imposed by food availability. When food access is restricted, functions which are coupled more or less directly to food ingestion are shifted to the time of food access, whether it is during light or of dark hours. The marked decrease of oxygen consumption in FAST fish during the light phase and sequential increase at dark phase may be linked to a "return" to the species natural biology rhythm once the feeding stimuli disappeared. Despite the possibility to adapt to forced circadian rhythms, the consequences of such change in the metabolic plasticity of the individuals have never been addressed. In addition, the high metabolic scope found during the light phase might be an adaptative strategy to food availability in captivity.

The present study shows a higher metabolic scope due to feeding (the difference between FEED and FAST oxygen consumption rates) in the light phase (see Fig. 1), when average data are analysed. However, correlation analysis did not show any relation between resting metabolism and metabolic scope due to feeding in individual fish, as would then be expected, because when we have higher oxygen consumption fasting values we have lower values of metabolic scope due to feeding once these values are the difference between feed and fasted metabolism. This apparent lack of consistency between mean and individual data could be explained if individuals with lower resting metabolic rates tend to be the ones with higher fed metabolic rates. However, the opposite was observed in the present study (see Fig. 5). A more likely explanation is that individual Senegalese sole juveniles have different strategies to accommodate the energetic costs of maintenance and growth. In some individuals these costs are additive, and in others when fish grow at maximal rates the costs of maintenance (FAST metabolic rate) are partly suppressed, creating additional scope for growth. The occurrence of such non-additive for the energetic costs of maintenance and growth has been previously suggested for other fish species (Rombough, 1994; Conceição et al., 1998). It would be interesting to verify to what extent these proposed different strategies to accommodate the energetic costs of maintenance and growth correlate with the different coping styles recently suggested for Senegalese sole (Silva et al., 2010).

In conclusion, this study provided basic knowledge on the metabolic rate rhythms of Senegalese sole juveniles. In fasted fish the highest oxygen consumption measurements were observed during the dark phase, emphasising the synchrony between species biological cycle and oxygen consumption. However, when food was provided during the light phase, juveniles were capable of shifting their oxygen consumption rhythms to respond to the energetic demands of digestion and growth. 


\section{Acknowledgements}

C.I.M. Martins and S. Engrola acknowledge the financial support by Fundação para a Ciência e Tecnologia, Portugal, through grants SFRH/ BPD/42015/2007 and SFRH/BPD/49051/2008, respectively. This study benefited from funding by Project ECOAQUA 5.E (programme POCTEP, co-funded by FEDER, European Commission). The authors are grateful to João Reis for developing the respirometry setup and the Oxylogger software. [RH]

\section{References}

Aranda, A., Madrid, J.A., Zamora, A., Sánchez-Vázquez, S., Sánchez-Vázquez, F.J., 1999 Synchronizing effect of photoperiod on the dual phasing of demand-feeding rhythms in sea bass. Biological Rhythm Research 30, 392-406.

Bayarri, M.J., Muñoz-Cueto, J.A., López-Olmeda, J.F., Vera, L.M., Rol de Lama, M.A., Madrid, J.A., Sánchez-Vázquez, F.J., 2004. Daily locomotor activity and melatonin rhythms in Senegal sole (Solea senegalensis). Physiology \& Behavior 81, 577-583.

Biswas, A.K., Endo, M., Takeuchi, T., 2002. Effect of different photoperiod cycles on metabolic rate and energy loss of both fed and unfed young tilapia, Oreochromis niloticus: Part I. Fisheries Science 68, 465-477.

Brett, J.R., 1971. Energetic responses of salmon to temperature. A study of some thermal relations in the physiology and freshwater ecology of sockeye salmon (Oncorhynchus nerkd). Amer Zool 11, 99-113.

Brett, J.R., Groves, T.D.D., 1979. Physiological energetics. In: J.R (Ed.), Fish Physiology Academic Press, New York, pp. 279-352.

Careau, V., Thomas, D., Humphries, M.M., Réale, D., 2008. Energy metabolism and animal personality. Oikos 117, 641-653.

Conceição, L.E.C., Dersjant-Li, Y. \& Verreth, J.A.J., 1998. Cost of growth in larval and juvenile African catfish (Clarias gariepinus) in relation to growth rate, food intake and oxygen consumption. Aquaculture 161, 95-106.

Cunha, I., Conceição, L.E.C., Planas, M., 2007. Energy allocation and metabolic scope in early turbot, Scophthalmus maximus, larvae. Marine Biology 151, 1397-1405.

Davis, R.E., 1962. Daily rhythm in the reaction of fish to light. Science 137, 430-432.

De la Gándara, F., García-Gómez, A., Jover, M., 2002. Effect of feeding frequency on the daily oxygen consumption rhythms in young Mediterranean yellowtails (Seriola dumerili). Aquacultural Engineering 26, 27-39.

Dinis, M.T., Ribeiro, L., Soares, F., Sarasquete, C., 1999. A review on the cultivation potential of Solea senegalensis in Spain and in Portugal. Aquaculture 176, 27-38.

Froy, O., Miskin, R., 2007. The interrelations among feeding, circadian rhythms and ageing. Progress in Neurobiology 82, 142-150.

Froy, O., Chapnik, N., Miskin, R., 2006. Long-lived \{alpha\}MUPA transgenic mice exhibit pronounced circadian rhythms. Am J Physiol Endocrinol Metab 291, E1017-E1024.

Fry, F.E.J., 1957. The aquatic respiration of fish. In: M.E., B. (Ed.), The Physiology of Fishes. Academic Press, New York.

Fry, F.E.J., 1971. The effect of environmental factors on the physiology of fish. In: Hoar, W.S., Randall, D.J. (Eds.), Fish Physiology. Academic Press, pp. 1-98.

Fu, S.-J., Cao, Z.-D., Peng, J.-L., 2006. Effect of meal size on postprandial metabolic response in Chinese catfish (Silurus asotus Linnaeus). Journal of Comparative Physiology B: Biochemical, Systemic, and Environmental Physiology 176, 489-495.

Jobling, M., 1981. The influence of feeding on the metabolic rate of fishes: a short review. Journal of Fish Biology 18, 385-400.
Jobling, M., 1994. Fish Bioenergetics. Chapman \& Hall, London, UK. 309 pp.

Lucas, M.C., Priede, I.G., 1992. Utilization of metabolic scope in relation to feeding and activity by individual and grouped zebrafish, Brachydanio rerio (HamiltonBuchanan). Journal of Fish Biology 41, 175-190.

Martins, C.I.M., Castanheira, M.F., Engrola, S., Costas, B., Conceição, L.E.C., 2011. Individual differences in metabolism predict coping styles in fish. Applied Animal Behaviour Science 130, 135-143.

Moore, R.Y., Danchenko, R.L., 2002. Paraventricular-subparaventricular hypothalamic lesions selectively affect circadian function. Chronobiology International 19, 345-360.

Mrosovsky, N., 1996. Locomotor activity and nonphotic influences on circadian clocks. Biol. Rev. Camb. Philos. Soc. 71, 343-372.

Oliveira, C., Dinis, M.T., Soares, F., Cabrita, E., Pousão-Ferreira, P., Sánchez-Vázquez, F.J., 2009. Lunar and daily spawning rhythms of Senegal sole, Solea senegalensis. Journal of Fish Biology 75, 61-74.

Reebs, S.G., 2002. Plasticity of diel and circadian activity rhythms in fishes. Reviews in Fish Biology and Fisheries 12, 349-371.

Reig, L., Ginovart, M., Flos, R., 2003. The application and evaluation of an individual marking technique of sole fingerlings (Solea sp.) for studies of growth. Journal of Applied Ichthyology 49-51.

Rombough, P.J., 1994. Energy partitioning during fish development: additive or compensatory allocation of energy to support growth? Functional Ecology 8, $178-186$.

Ross, L.G., McKinney, R.W., 1988. Respiratory cycles in Oreochromis niloticus (L.), measured using a six-channel microcomputer-operated respirometer. Comparative Biochemistry and Physiology Part A: Physiology 89, 637-643.

Rubin, N.H., Alinder, G., Rietveld, W.J., Rayford, P.L., Thompson, J.C., 1988. Restricted feeding schedules alter the circadian rhythms of serum insulin and gastric inhibitory polypeptide. Regulatory Peptides 23, 279-288.

Sánchez, J.A., López-Olmeda, J.F., Blanco-Vives, B., Sánchez-Vázquez, F.J., 2009. Effects of feeding schedule on locomotor activity rhythms and stress response in sea bream. Physiology \& Behavior 98, 125-129.

Sánchez-Vázquez, F.J., Azzaydi, M., Martinez, F.J., Zamora, S., Madrid, J.A., 1998. Annual rhythms of demand-feeding activity in sea bass: evidence of a seasonal phase inversion of the diel feeding pattern. Chronobiology International 15, 607-622.

Seppänen, E., Piironen, J., Huuskonen, H., 2010. Consistency of standard metabolic rate in relation to life history strategy of juvenile Atlantic salmon Salmo salar. Comparative Biochemistry and Physiology - Part A: Molecular \& Integrative Physiology 156, 278-284.

Silva, P.I.M., Martins, C.I.M., Engrola, S., Marino, G., Øverli, Ø., Conceição, L.E.C., 2010. Individual differences in cortisol levels and behaviour of Senegalese sole (Solea senegalensis) juveniles: evidence for coping styles. Applied Animal Behaviour Science $124,75-81$.

Souêtre, E., Salvati, E., Belugou, J.-L., Pringuey, D., Candito, M., Krebs, B., Ardisson, J.-L., Darcourt, G., 1989. Circadian rhythms in depression and recovery: evidence for blunted amplitude as the main chronobiological abnormality. Psychiatry Research 28, 263-278.

Vera, L.M., Oliveira, C.D., López-Olmeda, J.F., Ramos, J., Mañanós, E., Madrid, J.A., Sánchez-Vázquez, F.J., 2007. Seasonal and daily plasma melatonin rhythms and reproduction in Senegal sole kept under natural photoperiod and natural or controlled water temperature. Journal of Pineal Research 43, 50-55.

Wieser, W., 1985. Developmental and metabolic constraints of the scope for activity in young rainbow trout (Salmo gairdneri). Journal Experimental Biology 118, 133-142. 